\title{
Tidal volume measurements in the delivery room in preterm infants requiring positive pressure ventilation via endotracheal tube- feasibility study
}

\author{
Ruben Vaidya $\mathbb{D}^{1} \cdot$ Paul Visintainer ${ }^{2} \cdot$ Rachana Singh $^{3}$ \\ Received: 8 February 2021 / Revised: 5 May 2021 / Accepted: 18 May 2021 / Published online: 10 June 2021 \\ (C) The Author(s), under exclusive licence to Springer Nature America, Inc. 2021
}

\begin{abstract}
Objective Current delivery room (DR) resuscitation utilizes pressure-limited devices without tidal volume (TV) measurements. Clinicians use chest expansion as a surrogate, which is a poor indicator of TV. TV in early life can be highly variable due to rapidly changing lung compliance. Our objectives were to assess feasibility of measuring TV in DR, and to report the generated TV in intubated patients.

Study design Prospective, observational, feasibility study in infants $<32$ weeks GA and intubated in DR. TV was measured using a respiratory function monitor.

Result Ten infants with mean GA 23.9( \pm 1.5$)$ weeks and mean BW 618.5( \pm 155$)$ gram were included. Total of $178 \mathrm{~min}$ (mean $17.8 \mathrm{~min} /$ patient) with 8175 individual breaths (mean 817.5 breaths $/$ patient) were analyzed. Goal TV of $4-6 \mathrm{ml} / \mathrm{kg}$ was provided $23.5 \%$ of times with high TV ( $>6 \mathrm{ml} / \mathrm{kg}$ ) provided $47.7 \%$ of times.

Conclusion TV measurement in DR is feasible. It is associated with high intra and inter-patient variability.
\end{abstract}

\section{Background}

Bronchopulmonary dysplasia (BPD) is one of the most common morbidity associated with preterm birth, with $\sim 35 \%$ incidence in extremely low gestational age (GA) infants [1-3]. The pathogenesis of BPD is multifactorial with lung injury from mechanical ventilation, oxygen toxicity, and antenatal or postnatal infections all playing a key role. Delivery room (DR) management of preterm infants during the initial resuscitation has a significant

The abstract of this study has presented at the Pediatric Academic Society meeting, 2021.

Ruben Vaidya

ruben.vaidya@baystatehealth.org

1 Division of Newborn Medicine, Department of Pediatrics, University of Massachusetts Medical School-Baystate, Springfield, MA, USA

2 Epidemiology and Biostatistics Research Core, Office of Research, University of Massachusetts Medical School-Baystate, Springfield, MA, USA

3 Division of Newborn Medicine, Department of Pediatrics, Tufts Children's Hospital, Boston, MA, USA impact on development of BPD [4], and non-invasive respiratory support and lower oxygen concentration during resuscitation have been shown to be associated with improved outcomes [5].

Current DR resuscitation focuses on pressure-limited (PL) devices that lack the ability to measure delivered tidal volume (TV) [6]. Clinicians provide pressure-limited ventilation (PLV) using either a self-inflating bag or a T-piece resuscitator, where the provider regulates the inflation pressure and inflation time, but not the TV. Clinicians often rely on chest expansion as a surrogate measure for delivered TV, which is known to be a poor indicator of TV [7], and many infants can receive inappropriate $\mathrm{TV}$ within minutes of birth leading to either barotrauma, volutrauma, and/or atelectotrauma [8].

Preterm lungs have highly variable lung compliance due to low surfactant production, variable chest wall compliance and need for positive pressure ventilation (PPV) leading to rapid fluid shifts in the immediate newborn period. With rapidly changing pulmonary compliance, PLV can lead to significant variability in the delivered TV. Reports suggest that PL resuscitation devices routinely used in the DR can triple the intended TV during PPV in a newborn manikin [9]. Large TV can lead to volutrauma and/or barotrauma with negative outcomes. A study in preterm lambs reported as few as six large TV breaths at birth can lead to acute lung 


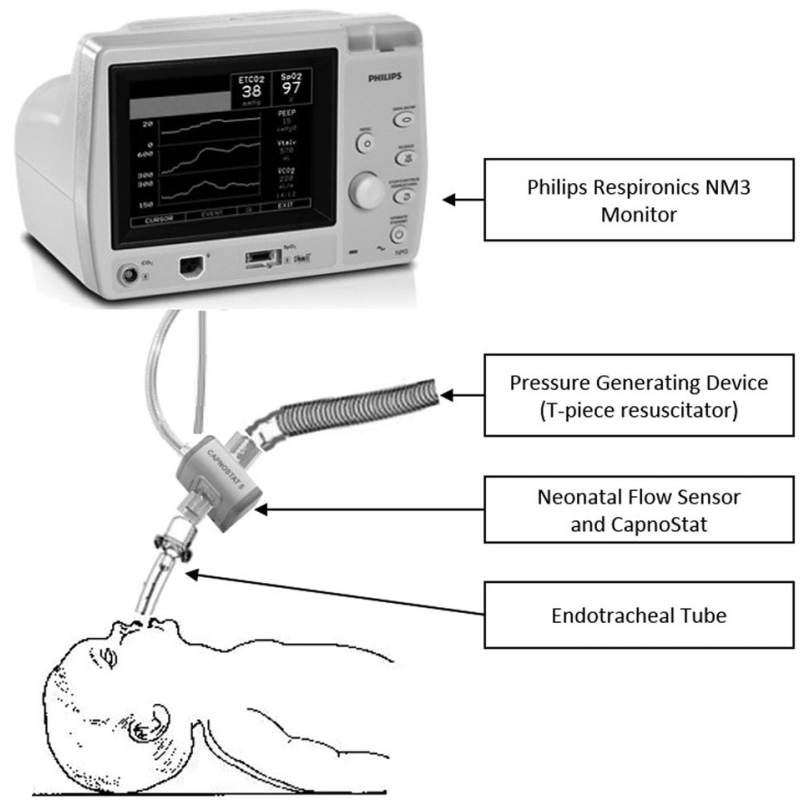

Fig. 1 Schematic diagram demonstrating the use of the respiratory function monitor. The tidal volume reported on the respiratory funtion monitor is measured with the help of the neonatal flow sensor placed between the endotracheal tube and the pressure-generating device.

injury and blunt the effect of subsequent surfactant treatment [10]. Ventilation with large breaths may cause gross overexpansion of regions that are forced open, resulting in epithelial and microvascular injury with subsequent pulmonary edema, making the lung parenchyma more susceptible to volutrauma during conventional mechanical ventilation [11]. Several studies have demonstrated that PPV with TV more than $8 \mathrm{ml}$ per $\mathrm{kg}$ causes lung inflammation and lung injury [10,12-14], and may also result in brain inflammation and injury [6,15-17]. The risk of lung injury is likely related to the magnitude of the volutrauma at birth, and therefore ventilation immediately after birth needs to be very gentle [15].

No study has specifically evaluated and reported the ability to measure TV provided in intubated preterm infants in the DR. We hypothesized that measurement of TV in intubated preterm infants $<32$ weeks in the DR is feasible, and that the TV generated via PLV in the immediate neonatal transition phase will be highly variable. Our specific objectives were to assess the percentage of times the resuscitating team had all the equipment ready in DR to measure TV, and to measure the infant's TV when receiving PLV in the DR through an endotracheal tube (ETT).

\section{Methods}

This study was a prospective, observational, noninterventional feasibility study. All preterm infants born
$<32$ weeks GA at Baystate Medical Center, a regional perinatal referral center with a Level III Neonatal Intensive Care Unit (NICU), without known significant cardiorespiratory anomalies and requiring PPV via an ETT in the DR were included in the study. Being a feasibility study, a convenience sample of ten consecutive patients was chosen.

We used a respiratory function monitor (RFM) with a flow sensor placed in series between the ETT and pressuregenerating device (T-piece resuscitator) to measure the breath-to-breath TV. The RFM used was Respironics NM3 monitor (Philips Healthcare, Eindhoven, Netherlands), which is a portable device, weighs $4.38 \mathrm{~kg}$ with dimensions of $21 \mathrm{~cm} \times 29.2 \mathrm{~cm} \times 23.5 \mathrm{~cm}$ (height $\times$ wide $\times$ depth) with an internal battery which can last up to $45 \mathrm{~min}$ on a full charge (https://philipsproductcontent.blob.core.windows. net/assets/20170523/1b0ab24074ae445ab043a77c014c2ccf. pdf). It has two attachments: a disposable flow sensor which measures the flow and TV, and a Capnostat-5 sensor, which is a carbon dioxide sensor. The two components attach to form a unit, which after fixing of the ET tube, were attached between the ET tube and the pressure-generating device to measure the TV (Fig. 1). The Capnostat-5 sensor weighs less than $18 \mathrm{~g}$, and strict precautions were taken to avoid accidental extubation or tension on the ET tube from the weight of the devices. The flow sensor adds less than $1 \mathrm{ml}$ of airway dead space volume for neonatal sensors (ETT size of $2.5-4 \mathrm{~mm}$ ). Providers were blinded from the actual TV measurements; hence no interventions were performed based on the TV measurements. Data were continuously collected as infants received PPV via ETT until connected to a mechanical ventilator in the NICU. The study was approved by Baystate Medical Center Institutional Review Board and is registered at clinicaltrials.gov (NCT03938532). The authors had no financial conflicts of interest to declare or had any relationship with Philips Healthcare. A deferred written informed consent was obtained from the parents for the infants who participated in the study.

\section{Statistical analysis}

As the study was designed as a pilot, no formal tests of hypotheses were conducted [18]. Our goal was to attain skill and competency with using the device and to estimate the distributional properties of the clinical measures of interest. Descriptive statistics were used to assess the feasibility of measuring TV in the DR. Feasible was defined as being able to successfully measure the TV in $80 \%$ of the infants within 60 seconds of starting PPV via the ETT. In addition, the pilot data generated will then be used to estimate effect sizes and variability so that sample size and statistical power may be computed for a later randomized 
control trial. The study was not powered to evaluate differences in long-term pulmonary outcomes like BPD, or to evaluate the safety and other long-term outcomes. The association between TV and peak inspiratory pressure (PIP) was assessed using a multilevel regression model that accounted for the within-patient correlation among multiple measures. We incorporated a random slope, as well as a random intercept, thus allowing us to assess the consistency of the relationship between PIP and TV across patients, while accounting for individual patient variability. The relationship between PIP and TV is reported as a regression coefficient with $95 \%$ confidence interval. A coefficient near zero would indicate no linear relationship between the two measures.

\section{Results}

Ten infants were included in the study with a mean GA of $23.9 \pm 1.5$ weeks and mean birth weight of $618.5 \pm 155 \mathrm{~g}$. Basic demographic information of all the subjects is reported in Table 1. Four of the infants received surfactant in the DR.

Measurement of TV in the DR was considered feasible, as $100 \%$ of the time all equipment were functioning and the TV measures were available on the RFM within $<60 \mathrm{sec}-$ onds of attaching the flow sensor. As strict precautions were taken to avoid tension on the ET tube, there were no cases of accidental extubation in our cohort during the study period. There were no reports or concerns regarding the difficulty in ventilation due to the additional devices from the providers.

A total of $178 \mathrm{~min}$ (mean $17.8 \mathrm{~min} /$ patient) of data with 8175 individual breaths (mean 817.5 breaths/patient) were available for analysis. The TVs were averaged over $1 \mathrm{~min}$ interval automatically by the RFM. Goal TV of $4-6 \mathrm{ml} / \mathrm{kg}$ was provided $23.6 \%$ of the times, low TV $(<4 \mathrm{ml} / \mathrm{kg})$ was provided $28.6 \%$, and high $\mathrm{TV}(>6 \mathrm{ml} / \mathrm{kg}$ ) was provided

Table 1 Subject characteristics.

\begin{tabular}{ll}
\hline & $\begin{array}{l}\text { All Subjects } \\
N=10\end{array}$ \\
\hline Gestation, weeks, mean \pm SD, weeks & $23.9 \pm 1.5$ \\
Birth weight, g, mean \pm SD, g & $618.5 \pm 155$ \\
Male, $n(\%)$ & $6(60 \%)$ \\
Cesarean section, $n(\%)$ & $6(60 \%)$ \\
Full course of antenatal steroids, $n(\%)$ & $8(80 \%)$ \\
1-min Apgar score, median (IQR) & $3(2-4)$ \\
5-min Apgar score, median (IQR) & $5(4-6)$ \\
Chorioamnionitis, $n(\%)$ & $5(50 \%)$
\end{tabular}

$S D$ standard deviation.
$47.7 \%$ of times. In addition, TV was $>8 \mathrm{ml} / \mathrm{kg}$ for $35.3 \%$ and $>10 \mathrm{ml} / \mathrm{kg} 19.1 \%$ of times, respectively. Additional RFM data are reported in Table 2.

Regarding the relationship between PIP and TV, there was wide variability among, as well as within, patients as demonstrated in Fig. 2. The linear relationship between PIP and TV was nearly zero (beta coefficient $=0.09,95 \% \mathrm{CI}$ :

Table 2 Respiratory function monitoring results.

\begin{tabular}{|c|c|}
\hline & $\begin{array}{l}\text { All patients } \\
(n=10)\end{array}$ \\
\hline Total number of inflations assessed & 8175 \\
\hline Average number of inflations per infant, mean \pm SD & $817.5 \pm 15.6$ \\
\hline Total minutes of data assessed & 178 \\
\hline Minutes of data assessed per patient $(\mathrm{min})$, mean $\pm \mathrm{SD}$ & $17.8 \pm 4.9$ \\
\hline $\mathrm{PIP}\left(\mathrm{cm} \mathrm{H} \mathrm{H}_{2} \mathrm{O}\right)$, mean $\pm \mathrm{SD}$ & $24.4 \pm 5$ \\
\hline PEEP $\left(\mathrm{cm} \mathrm{H}_{2} \mathrm{O}\right)$, mean $\pm \mathrm{SD}$ & $5.9 \pm 2.4$ \\
\hline Delta P (PIP-PEEP) $\left(\mathrm{cm} \mathrm{H}_{2} \mathrm{O}\right)$, mean $\pm \mathrm{SD}$ & $18.4 \pm 4.6$ \\
\hline MAP $\left(\mathrm{cm} \mathrm{H}_{2} \mathrm{O}\right)$, mean \pm SD & $12.9 \pm 3.2$ \\
\hline $\mathrm{TV}(\mathrm{ml} / \mathrm{kg})$, mean $\pm \mathrm{SD}$ & $6.6 \pm 3.4$ \\
\hline TV (ml/kg), median (IQR) & $5.7(3.8-8.9)$ \\
\hline Number of min with TV $4-6 \mathrm{ml} / \mathrm{kg}, \min (\%)$ & $42(23.6)$ \\
\hline Number of min with $\mathrm{TV}<4 \mathrm{ml} / \mathrm{kg}$, $\min (\%)$ & $51(28.6)$ \\
\hline Number of min with $\mathrm{TV}>6 \mathrm{ml} / \mathrm{kg}, \min (\%)$ & $85(47.7)$ \\
\hline Number of min with $\mathrm{TV}>8 \mathrm{ml} / \mathrm{kg}$, $\min (\%)$ & $63(35.3)$ \\
\hline Number of min with $\mathrm{TV}>10 \mathrm{ml} / \mathrm{kg}, \min (\%)$ & $34(19.1)$ \\
\hline
\end{tabular}

$P I P$ peak inspiratory pressure, $P E E P$ peak end expiratory pressure, $P$ pressure, $M A P$ mean airway pressure, $T V$ tidal volume.

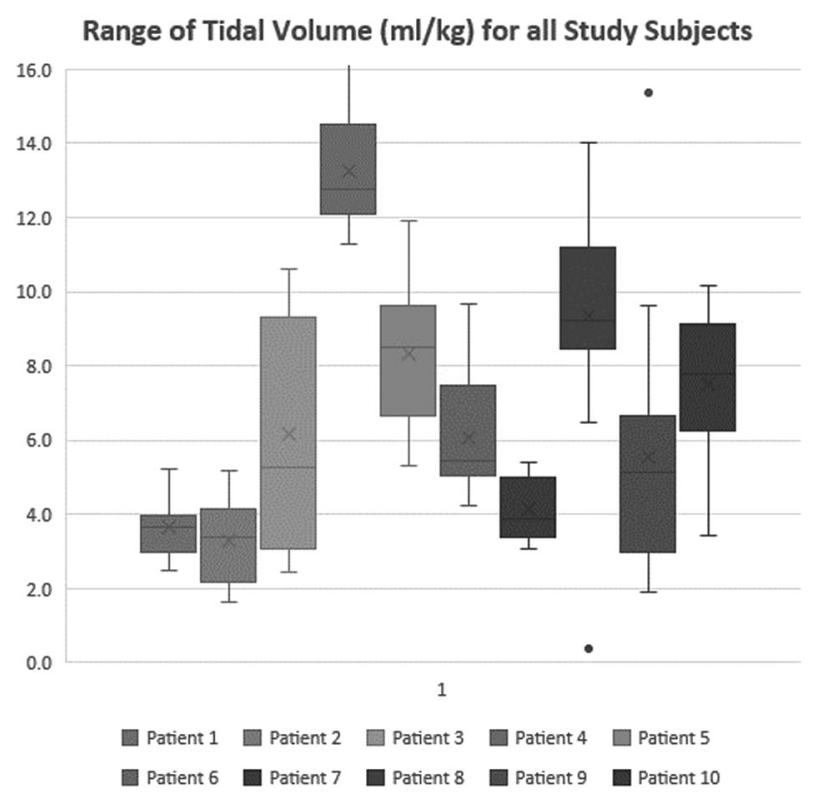

Fig. 2 Range of Tidal Volume delivered for all study subjects. Range of Tidal Volume delivered for all study subjects. There was a wide intra and inter-patient variability in measured tidal volume in the delivery room in intubated preterm infants. 


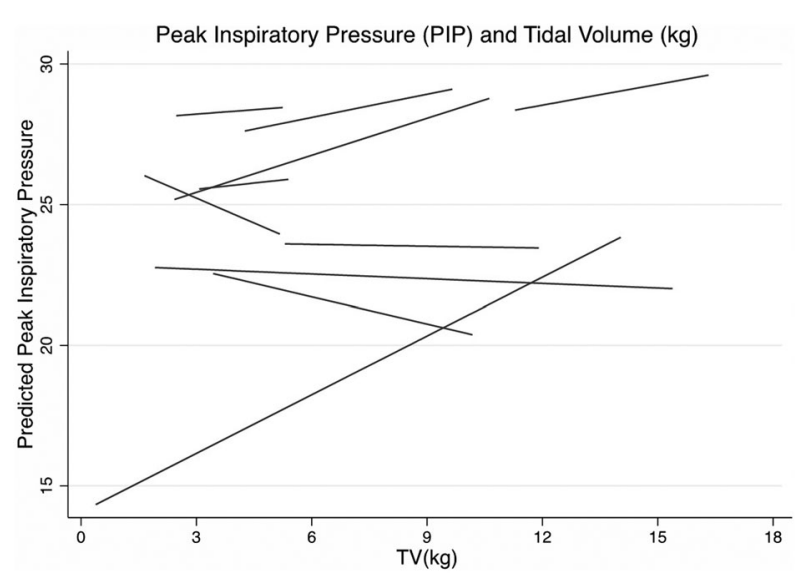

Fig. 3 Individual subject correlation between peak inspiratory pressure and tidal volume. There was high degree of intra- and interpatient variability in tidal volume measurements, with highly variable relationship with peak inspiratory pressure among individuals.

$-0.25,0.44 ; p=0.60$ ) (Fig. 3 shows the substantial variability in the relationship between PIP and TV).

\section{Discussion}

This is the first study to report the feasibility of measuring delivered TV during DR resuscitation with PPV via the ETT in preterm infants. The ability to setup the RFM and measure TV within $<60$ seconds of intubation in $100 \%$ of subjects is highly encouraging for clinical translation. The resuscitation team was provided a brief one-time tutorial in the setup and application of the RFM probe with subsequent implementation once the study started recruitment. The team expressed high level of comfort in using the device and no complications were reported. One study evaluating the use of RFM in the DR focused on improving mask PPV and inferred the use of RFM in the DR to be feasible and not associated with any problems. Also, PPV guided by a display of pressure, TV, and mask leak data from the RFM was associated with significantly less mask leak, more adjustments of mask position and airway pressure, and lower rate of excessive TV [19].

In our small sample of subjects, we report a wide variability in the delivered TV within the same patient and in between different patients. This possibly may be secondary to wide variations in pulmonary compliance in preterm lung as well as inter- and intra-operator ability to deliver identical breaths; making regulation of TV with a PL device challenging. Studies of preterm infants have defined an 'appropriate' exhaled TV range of $4-8 \mathrm{~mL} / \mathrm{kg}$ during phasic PPV [20, 21]. Studies assessing TV delivered during resuscitation using a $\mathrm{T}$-piece device via a mask have also reported a wide variability in TV that ranged from 0 to $>30$ $\mathrm{ml} / \mathrm{kg}$, with $85 \%$ of preterm infants receiving excessively high VT ( $>8 \mathrm{ml} / \mathrm{kg}$ ) [8]. However, mask ventilation is often hampered by large leak and obstruction [22-24], hence an accurate measurement of the delivered TV may be difficult. Since we measured TV in an intubated infant, there would potentially be less likelihood of a big leak and/or obstructive component, and our results may reflect a more accurate measurement of the TV in an intubated subject.

It was striking that in our study $19.1 \%$ of times subject received $\mathrm{TV}>10 \mathrm{ml} / \mathrm{kg}$, even though the T-piece resuscitators were set at the recommended PIP and positive end expiratory pressure. Other studies reporting TV measured during noninvasively PPV via a mask also reported high prevalence of large $\mathrm{TV}>6 \mathrm{ml} / \mathrm{kg}$ during resuscitation [22, 25], with one study reporting its prevalence as high as $75 \%$ [17]. It is well established that even five large rapid inflations $(>8 \mathrm{ml} / \mathrm{kg})$ at birth can cause lung injury [10] and initiate a systemic inflammatory cascade [13]. Studies using RFM in the DR for non-invasive PPV have demonstrated that large TV may be associated with intraventricular hemorrhage [26] and brain injury [17]. The bag-and-mask or T-piece circuits commonly used for neonatal resuscitation provide no feedback information on the delivered TV, hence it is poorly controlled and can potentially expose the preterm neonate to volutrauma [6]. Ventilation with targeted TV is an accepted ventilator management in many NICUs to minimize lung damage [27], but DR practices continues to focus on PLV.

Our study is limited by a small sample size as it was a feasibility study, and it was not powered to assess long-term outcomes. We were also unable to uniformly analyze the exact time points where the TV were out of range in regards to the age of the infant, as the first measured TV ranged from 2 to $12 \mathrm{~min}$ depending on delayed cord clamping, duration of initial PPV, attempts at allowing spontaneous breathing with non-invasive respiratory support, the number of intubation attempts needed and time to fix the ET tube. The major strength of our study is that it is a prospective cohort of subjects at the highest risk of BPD, all deliveries were at academic tertiary Level III NICU, attended by NICU team lead by a neonatologist with uniform DR practices following NRP guidelines. The goal of this study was not to report the ideal TV for infant during resuscitation, rather evaluate feasibility of measuring TV in the DR, to report wide inter and intra-patient TV variation, and to encourage further studies to assess the significance of these results. The TV needed to displace the fetal lung fluid and initially aerate the preterm lung is largely unknown [28] and it is likely that higher TVs may be needed initially needed to facilitate fetal lung fluid clearance, initiate alveolar ventilation, and establish the functional residual capacity (FRC), as compared to the subsequent ventilation post-alveolar recruitment and achievement of FRC [29]. The significance of these results is unclear but delivering such large $\mathrm{TV}>8 \mathrm{ml} / \mathrm{kg}$ and/or $>10 \mathrm{ml} / \mathrm{kg}$ should be concerning, and 
further studies are required to replicate these results and assess its significance. Also, future studies should focus on assessing the ideal TV to be delivered in the DR to promote fetal lung fluid clearance, but at the same time provide gentle ventilation and prevent volutrauma.

In conclusion, we report that measurement of delivered TV via ETT in the DR is feasible in preterm infants using a RFM. There is a high degree of intra- and inter-subject variability in delivered TV with potential to cause volutrauma. More studies are needed to evaluate the significance of these results.

\section{Data availability}

The data from the current study are available from the corresponding author on reasonable request, upon completion of regulatory and institutional regulations and requirements.

Acknowledgements We thank Baystate Medical Center, Office of Research for grant funding, and the Department of Pediatrics for continuing research support.

Funding The study is supported by Research Pilot Award Program (RPAP), Baystate Medical Center. The funder/sponsor was not involved in this work in any form.

Author contributions Concept, design, acquisition, analysis, interpretation of data, critical review of manuscript: RV, PV, RS; Initial drafting of the manuscript: RV; Statistical analysis: RV, PV.

\section{Compliance with ethical standards}

Conflict of interest The authors have no relationship with Philips Healthcare, and have no financial conflicts of interest to declare in association with the currently submitted manuscript.

Ethical approval and consent to participate The study was approved by Baystate Medical Center Institutional Review Board (BH-19-006) and is registered at clinicaltrials.gov (NCT03938532). A deferred written informed consent was obtained from the parents for the infants who participated in the study.

Publisher's note Springer Nature remains neutral with regard to jurisdictional claims in published maps and institutional affiliations.

\section{References}

1. Thébaud B, Goss KN, Laughon M, Whitsett JA, Abman SH, Steinhorn RH, et al. Bronchopulmonary dysplasia. Nat Rev Dis Prim. 2019;5:78.

2. Lapcharoensap W, Gage SC, Kan P, Profit J, Shaw GM, Gould $\mathrm{JB}$, et al. Hospital variation and risk factors for bronchopulmonary dysplasia in a population-based cohort. JAMA Pediatr. 2015;169: e143676.

3. Geary C, Caskey M, Fonseca R, Malloy M. Decreased incidence of bronchopulmonary dysplasia after early management changes, including surfactant and nasal continuous positive airway pressure treatment at delivery, lowered oxygen saturation goals, and early amino acid administration: a historical cohort study. Pediatrics. 2008;121:89-96.

4. Kim SH, Han YS, Chun J, Lee MH, Sung TJ. Risk factors that affect the degree of bronchopulmonary dysplasia: Comparison by severity in the same gestational age. PLoS ONE. 2020;15:e0235901.

5. Foglia EE, Jensen EA, Kirpalani H. Delivery room interventions to prevent bronchopulmonary dysplasia in extremely preterm infants. J Perinatol. 2017;37:1171-9.

6. Polglase GR, Miller SL, Barton SK, Kluckow M, Gill AW, Hooper SB, et al. Respiratory support for premature neonates in the delivery room: effects on cardiovascular function and the development of brain injury. Pediatr Res. 2014;75:682-8.

7. Poulton DA, Schmölzer GM, Morley CJ, Davis PG. Assessment of chest rise during mask ventilation of preterm infants in the delivery room. Resuscitation. 2011;82:175-9.

8. Schmölzer GM, Kamlin OC, O’Donnell CP, Dawson JA, Morley CJ, Davis PG. Assessment of tidal volume and gas leak during mask ventilation of preterm infants in the delivery room. Arch Dis Child Fetal Neonatal Ed. 2010;95:F393-7.

9. Solevåg AL, Haemmerle E, van Os S, Bach KP, Cheung PY, Schmölzer GM. Comparison of positive pressure ventilation devices in a newborn manikin. J Matern Fetal Neonatal Med. 2017;30:595-9.

10. Björklund LJ, Ingimarsson J, Curstedt T, John J, Robertson B, Werner $\mathrm{O}$, et al. Manual ventilation with a few large breaths at birth compromises the therapeutic effect of subsequent surfactant replacement in immature lambs. Pediatr Res. 1997;42:348-55.

11. Dreyfuss D, Soler P, Saumon G. Mechanical ventilation-induced pulmonary edema. Interaction with previous lung alterations. Am J Respir Crit Care Med. 1995;151:1568-75.

12. Wada K, Jobe AH, Ikegami M. Tidal volume effects on surfactant treatment responses with the initiation of ventilation in preterm lambs. J Appl Physiol. 1997;83:1054-61.

13. Hillman NH, Moss TJ, Kallapur SG, Bachurski C, Pillow JJ, Polglase GR, et al. Brief, large tidal volume ventilation initiates lung injury and a systemic response in fetal sheep. Am J Respir Crit Care Med. 2007;176:575-81.

14. Polglase GR, Hillman NH, Pillow JJ, Nitsos I, Newnham JP, Knox CL, et al. Ventilation-mediated injury after preterm delivery of Ureaplasma parvum colonized fetal lambs. Pediatr Res. 2010;67:630-5.

15. Polglase GR, Miller SL, Barton SK, Baburamani AA, Wong FY, Aridas JD, et al. Initiation of resuscitation with high tidal volumes causes cerebral hemodynamic disturbance, brain inflammation and injury in preterm lambs. PLoS ONE. 2012;7:e39535.

16. Skiöld B, Wu Q, Hooper SB, Davis PG, McIntyre R, Tolcos M, et al. Early detection of ventilation-induced brain injury using magnetic resonance spectroscopy and diffusion tensor imaging: an in vivo study in preterm lambs. PLoS ONE. 2014;9:e95804.

17. Mian Q, Cheung PY, O'Reilly M, Barton SK, Polglase GR, Schmölzer GM. Impact of delivered tidal volume on the occurrence of intraventricular haemorrhage in preterm infants during positive pressure ventilation in the delivery room. Arch Dis Child Fetal Neonatal Ed. 2019;104:F57-62.

18. Leon AC, Davis LL, Kraemer HC. The role and interpretation of pilot studies in clinical research. J Psychiatr Res. 2011;45:626-9.

19. Schmölzer GM, Morley CJ, Wong C, Dawson JA, Kamlin CO, Donath SM, et al. Respiratory function monitor guidance of mask ventilation in the delivery room: a feasibility study. J Pediatr. 2012;160:377-81.

20. Schmölzer GM, Te Pas AB, Davis PG, Morley CJ. Reducing lung injury during neonatal resuscitation of preterm infants. J Pediatr. 2008;153:741-5. 
21. Murthy V, Dattani N, Peacock JL, Fox GF, Campbell ME, Milner $\mathrm{AD}$, et al. The first five inflations during resuscitation of prematurely born infants. Arch Dis Child Fetal Neonatal Ed. 2012;97: F249-53.

22. Schilleman K, van der Pot CJ, Hooper SB, Lopriore E, Walther FJ, te Pas AB. Evaluating manual inflations and breathing during mask ventilation in preterm infants at birth. $\mathrm{J}$ Pediatr. 2013;162:457-63.

23. Schilleman K, Witlox RS, Lopriore E, Morley CJ, Walther FJ, te Pas AB. Leak and obstruction with mask ventilation during simulated neonatal resuscitation. Arch Dis Child Fetal Neonatal Ed. 2010;95:F398-402.

24. Kaufman J, Schmölzer GM, Kamlin CO, Davis PG. Mask ventilation of preterm infants in the delivery room. Arch Dis Child Fetal Neonatal Ed. 2013;98:F405-10.
25. Schmölzer GM, Kamlin OC, Dawson JA, te Pas AB, Morley CJ, Davis PG. Respiratory monitoring of neonatal resuscitation. Arch Dis Child Fetal Neonatal Ed. 2010;95:F295-303.

26. Pahuja A, Hunt $\mathrm{K}$, Murthy V, Bhat $\mathrm{P}$, Bhat $\mathrm{R}$, Milner $\mathrm{AD}$, et al. Relationship of resuscitation, respiratory function monitoring data and outcomes in preterm infants. Eur J Pediatr. 2018;177:1617-24.

27. Keszler M. State of the art in conventional mechanical ventilation. J Perinatol. 2009;29:262-75.

28. Foglia EE, Te Pas AB. Effective ventilation: the most critical intervention for successful delivery room resuscitation. Semin Fetal Neonatal Med. 2018;23:340-6.

29. van Vonderen JJ, van Zanten HA, Schilleman K, Hooper SB, Kitchen MJ, Witlox RS, et al. Cardiorespiratory monitoring during neonatal resuscitation for direct feedback and audit. Front Pediatr. 2016;4:38. 